\title{
A MIGRAÇÃO DAS IDEIAS CONSTITUCIONAIS: METAMORFOSES DA RECEPÇÃO DO ATIVISMO JUDICIAL NA DOUTRINA CONSTITUCIONAL BRASILEIRA
}

\section{Rogério Aparecido Fernandes de Carvalho*}

\section{Resumo}

O artigo tem por objetivo analisar a recepção do ativismo judicial na doutrina constitucional brasileira a partir da metodologia comparativista da migração das ideias constitucionais, contribuindo com novas reflexões sobre o fenômeno. Após esboçar algumas concepções de ativismo judicial no pensamento norte-americano com seus critérios comumente aceitos de compreensão epistêmica da categoria, são abordadas as concepções de uso corrente na doutrina constitucional brasileira e sua aclimatação em parcela da produção jurídicaacadêmica. Os resultados demonstram uma recepção metamorfoseada do fenômeno na doutrina constitucional brasileira com um duplo padrão de avaliação das práticas ativistas (o dualismo valorativo legítimo/ilegítimo).

Palavras-chave:

Ativismo judicial; decisionismo; judicialização; migração de ideais constitucionais; recepção de doutrinas constitucionais

\section{THE MIGRATION OF CONSTITUTIONAL IDEAS: METAMORPHOSES OF THE RECEPTION OF JUDICIAL ACTIVISM IN BRAZILIAN CONSTITUTIONAL DOCTRINE}

\begin{abstract}
The article aims to analyze the reception of judicial activism in the brazilian constitutional doctrine from the comparative methodology of the migration of constitutional ideas, contributing with new reflections on the phenomenon. After outlining some conceptions of judicial activism in north american thought with its commonly accepted criteria of epistemic understanding of the category, the conceptions currently used in brazilian doctrine and their acclimatization in a portion of legal-academic production are discussed. The results demonstrate a metamorphosed reception of the phenomenon in the brazilian constitutional doctrine with a double standard of evaluation of activist practices (the legitimate/illegitimate value dualism).
\end{abstract}

\section{Keywords:}

Judicial activism; decisionism; judicialization; migration of constitutional ideals; reception of constitutional doctrines

\footnotetext{
*Doutorando em Direito Público pela Universidade do Vale do Rio dos Sinos. Mestre em Direito Público pela Universidade do Vale do Rio dos Sinos. Especialista em Direito do Estado pela Universidade Federal do Rio Grande do Sul. Especialista em Direito Tributário Empresarial pela Fundação Getúlio Vargas. Bacharel em Direito pela Universidade Federal do Rio Grande do Sul.

E-mail: rogerio@fernandesdecarvalho.com.br.
} 


\section{Introdução}

As modificações do papel do judiciário no arranjo institucional dos poderes estatais nas últimas quatro décadas e seus tensionamentos com as fórmulas clássicas que emolduraram o Estado contemporâneo, em especial, a teoria da separação de poderes montesquiana e a teoria da democracia representativa majoritária, têm sido debatidas ao redor do mundo, e no Brasil, em uma profusão de estudos, desde meados da década de 1990, os quais acentuam a notável expansão do poder judicial por meio da categoria judicialização da política (Tate e Vallinder, 1995; Castro, 1997; Werneck Vianna et. al., 1999; Sweet, 2004; Hirschl, 2007; Veronese, 2009; Motta et al., 2010). O significado central forte ${ }^{1}$ de judicialização da política, na formulação hoje tornada clássica de Tate e Vallinder (1995, p. 13 e 27), é "o processo pelo qual cortes e juízes passam a elaborar e implementar políticas públicas, ou de forma crescente, passam a dominar a produção de políticas públicas, que foram elaboradas (ou presumem-se deveriam ter sido) por outros órgãos governamentais, em especial, legisladores e administradores". Trata-se de atuação na qual o judiciário expande as fronteiras jurisdicionais, supostamente, em detrimento dos demais poderes estatais na tomada de decisão política, tendo como seu lugar privilegiado de manifestação a jurisdição constitucional.

Não obstante este marco teórico mais recente, as discussões em torno do lugar do judiciário nas democracias constitucionais contemporâneas são longevas, sobretudo, no cenário norte-americano, cujo debate sobre a tensão entre constitucionalismo e democracia remonta às origens da promulgação de sua Constituição e ao momento tido como fundacional da judicial review, com o célebre caso Marbury v. Madison. Como justificar o exercício do controle de constitucionalidade por juízes não eleitos e não sujeitos a responsabilização política em uma democracia, a designada dificuldade contramajoritária (Bickel, 1986), teria se tornado a grande obsessão acadêmica norte-americana (Friedmann, 2002).

Nesse contexto, o tema do ativismo judicial se desenvolveu naquele país como uma categoria quase onipresente nas doutrinas constitucionais e na ciência política para análise e

\footnotetext{
${ }^{1}$ Em uma acepção fraca, judicialização de política seria a difusão dos métodos de decisão judicial para fora de seu próprio domínio, isto é, a migração da forma de decisão discricionária (tipicamente política) para um modo de decisão limitado por regras, à maneira dos juízes (Tate e Vallinder, 1995, p. 13 e 27).
} 
avaliação das instituições judiciais, notadamente, a partir da jurisprudência liberal da Corte Warren (1953-1969), com conotação geral negativa e com o traço característico de atribuição de desfuncionalidade à atuação judicial ao invadir as competências de outros poderes, particularmente, a função legislativa (Kmiec, 2003; Friedmann, 2002; Koerner, 2016).

O extenso panorama sobre a temática do ativismo judicial e sua complexidade podem ser notados pelos milhares de trabalhos produzidos há mais de meio século na doutrina jurídica e ciência política norte-americanas, onde foi gestado o conceito e no qual teve o seu mais profícuo desenvolvimento teórico-acadêmico com acirradas disputas em torno de seu sentido. Acresça-se que na cena americana o conceito alcançou presença na esfera pública, em especial na imprensa, além de ser mobilizado como recurso político no campo partidário.

Assim como ocorrera com a categoria judicialização da política, o ativismo judicial tem sido recepcionado no Brasil, em particular, no âmbito do direito constitucional (Barroso, 2009; Ramos, 2010; Tassinari, 2013). Com efeito, conforme será visto a seguir, os estudos constitucionais brasileiros sobre o ativismo judicial abarcam reflexões sobre os limites e as possibilidades da função judicial nos quadros da engenharia institucional brasileira, e o alcance e legitimidade do exercício do controle judicial de constitucionalidade na democracia constitucional. Entretanto, algumas questões remanescem não problematizadas devidamente: a categoria ativismo judicial, cuja gênese se deu nas disputas doutrinais da história intelectual americana, é apropriada para pensar esse conjunto de questões? É possível a migração das ideias constitucionais em ambientes sócio-históricos profundamente distintos? E como tem se dado a recepção do conceito de ativismo judicial na doutrina constitucional brasileira?

Malgrado seus limites, o presente artigo tem por objetivo analisar a recepção do ativismo judicial na doutrina constitucional brasileira, a partir da metodologia comparativista da migração das ideias constitucionais (Choudry, 2006), e será dividido em três partes: na primeira parte, serão esboçadas algumas concepções de ativismo judicial extraídas da doutrina constitucional norte-americana, a fim de identificarmos os critérios mais comumente aceitos acerca da compreensão epistêmica da categoria; na segunda parte, serão abordadas as concepções de ativismo judicial de uso corrente na doutrina constitucional brasileira, as quais possibilitam indicar duas dimensões valorativas generalizantes de sua recepção no país; por fim, será analisada parcela selecionada da produção jurídica-universitária sobre o ativismo judicial como meio de identificar sua aclimatação ao corpus doutrinário constitucional. 


\section{Concepções de ativismo judicial na experiência constitucional norte-americana}

A noção de ativismo judicial precede seu registro histórico formal, como mostra a crítica veemente da jurisprudência constitucional durante a Era Lochner² (1895-1937).

Se, hoje, considera-se a Era Lochner sinônimo de ativismo judicial conservador, identificada em anulações de leis de regulação do trabalho e da economia para favorecer os interesses econômicos das grandes corporações, o termo é conspicuamente ausente da literatura contemporânea ao período. A expressão ativismo judicial surgiu no debate público norte-americano, em 1947, atribuindo-se ao historiador Arthur Schlesinger o primeiro registro de sua utilização, em artigo publicado na revista não acadêmica Fortune Magazine, para distinguir os juízes da Suprema Corte americana em duas alas distintas, a do ativismo e a da autocontenção: o grupo de justices Black-Douglas acreditaria que a Suprema Corte poderia exercer um papel afirmativo na promoção do bem estar social, considerando a Suprema Corte como instrumento para atingir determinados e desejados resultados sociais, enquanto o grupo de justices Frankfurter-Jackson defenderia postura de judicial self-restraint, preocupando-se em não expandir as opções de julgamentos sobre as legislaturas (Kmiec, 2003, p. 1446-1447).

Após o artigo de Schlesinger alguns usos iniciais do termo ativismo judicial tiveram uma conotação positiva, refletindo a crença de que se deveria empregar a judicial review para salvaguardar os direitos básicos na democracia. Esta valoração se altera nos anos 1950, no período da jurisprudência da Corte Warren, especialmente, Brown v. Board of Education, de 1954, quando o termo recebeu conotação geral negativa, e passou a ser utilizado para criticar as decisões judiciais. O pioneirismo de Schlesinger em utilizar o nome não evitou sua falha em defini-lo com maior precisão. Selecionou-se, aqui, quatro concepções ${ }^{3}$ de ativismo judicial que refletem o maistream doutrinário constitucional americano sobre o fenômeno.

Concebendo o ativismo judicial como um conceito histórico, Kmiec (2003, p. 14631476) delineia cinco definições que apareceriam constantemente nas discussões acadêmicas e opiniões da Suprema Corte: a primeira é derrubar atos indiscutivelmente constitucionais de

\footnotetext{
${ }^{2}$ Nome oriundo do emblemático caso Lochner v. New York, de 1905, no qual a Suprema Corte invalidou lei do Estado de Nova York que fixava jornada máxima de trabalho para os empregados de padarias.

${ }^{3} \mathrm{~A}$ distinção entre conceito e concepção formulada por W. B. Gallie para descrever conceitos essencialmente contestados, se assenta no maior grau de abstração do conceito, que teria alguns significados compartilhados comuns, a partir do qual os critérios para sua aplicação são contestados de tal forma que não podem ser resolvidos; um conceito contestado resulta em diferentes concepções sobre o próprio conceito (Poscher, 2018, p. 03-04). Conceitos seriam proposições mais abstratas, enquanto as concepções corresponderiam aos refinamentos mais concretos ou às subinterpretações dessas proposições mais abstratas (Dworkin, 2014, p. 86).
} 
outros poderes para além dos mandamentos "claros" da Constituição (o problema evidente desta definição é que ela envolve definir o próprio significado dos conteúdos constitucionais; afinal, o que seriam atos "indiscutivelmente" constitucionais?); a segunda definição é ignorar precedentes (com a discussão sobre se o precedente ignorado é vertical - cortes inferiores ignoram os precedentes das cortes superiores em casos similares - ou horizontal - a corte ignora seus próprios precedentes em casos similares); a terceira definição é a denominada legislação judicial (criação judicial do juiz, introduzindo inovações na ordem jurídica).

A quarta definição é afastar-se dos métodos de interpretação canônicos (trata-se de definição imprópria para qualificar o ativismo, pois envolve a complexa tradição envolta com a interpretação constitucional, além da própria adesão a uma teoria interpretativa, opção que, por si só, não deixará de ser controversa; entretanto, nos Estados Unidos, esta definição relaciona-se às disputas teóricas encaminhadas pelo originalismo ${ }^{4}$ e sua pretensão de colocarse como o método correto de interpretação constitucional); enfim, a quinta definição é o de julgamento orientado a resultados: a decisão é ativista quando o juiz tem um motivo oculto (político/ideológico) para tomar a decisão, se afastando de algum padrão jurídico de correção.

Marshall (2002, p. 104) enumera sete índices, frequentemente, anotados na literatura constitucional para caracterização do fenômeno: o ativismo contramajoritário ${ }^{5}$ (a relutância das cortes em ter deferência às decisões de ramos democraticamente eleitos); o ativismo não originalista (o fracasso das cortes em ser deferente a alguma noção de originalismo ao decidir casos; como já referido, o critério é problemático, pois não se trata de doutrina universalmente aceita, estando vinculada ao campo dos juristas conservadores nos Estados Unidos); o ativismo precedencial (não deferência a precedentes); o ativismo jurisdicional ${ }^{6}$ (não adesão aos limites jurisdicionais de competência de seus poderes; tratar-se-ia da ultrapassagem ou redefinição dos contornos de institutos processuais e regras de exercício da jurisdição); a criatividade judicial na elaboração de novas teorias e direitos na doutrina constitucional ${ }^{7}$; o

\footnotetext{
${ }^{4} \mathrm{~A}$ vertente textual do originalismo propugna o respeito a literalidade do texto (enunciados linguísticos) da Constituição de 1787, enquanto a vertente intencional prega o respeito a intenção original dos pais fundadores. ${ }^{5}$ Este índice de ativismo não parece aceitável, pois ele significaria a fragilização do próprio constitucionalismo: a supremacia da Constituição é assegurada na jurisdição constitucional, exatamente, com a anulação/desaplicação da lei inconstitucional, sendo incabível equiparar a priori o ativismo judicial e o controle de constitucionalidade. ${ }^{6}$ Este índice do ativismo jurisdicional foi aplicado para analisar a postura do Supremo Tribunal Federal ao redefinir o alcance de sua própria competência jurisdicional por meio da reconfiguração jurisprudencial do alcance dos instrumentos processuais da reclamação e do mandado de injunção (Valle et al., 2012, p. 41-65).

${ }^{7}$ Não parece ser um índice adequado para aferição de ativismo, pois a criação de novas teorias na doutrina constitucional, se vinculadas à tradição e a arquitetura constitucional de um país, responderá às necessidades que surgem no tempo histórico de cada dada sociedade, haja vista a natureza histórica e contingente do direito.
} 
ativismo remedial $^{8}$ (uso do poder judicial para impor obrigações afirmativas a outros ramos governamentais ou colocá-los sob supervisão judicial como parte do cumprimento dos remédios judiciais impostos); o ativismo partidário - uso do poder judicial para implementar objetivos partidários - (apesar de sugerir aparente critério útil, esbarra nas dificuldades para se identificar uma ligação estrita e direta entre a decisão judicial e a vinculação partidária).

Analogamente aos critérios supracitados, Young (2002, p. 1139-1216) formula seis categorias de comportamento judicial que se identificariam com atitudes ativistas.

Essas categorias de práticas ativistas se unificam num ponto em comum: a tendência de aumentar o domínio de ação das cortes em face de outros ramos políticos. A primeira categoria, também concebida nos dois trabalhos precedentes, relaciona o ativismo com o poder de controlar a constitucionalidade das leis, conexão que deita raízes na questão da dificuldade contramajoritária, e, como visto, não pode ser considerado um signo distintivo de ativismo judicial, mas como traço essencial do próprio constitucionalismo contemporâneo.

A segunda categoria de Young (2002, p. 1139-1216) é o afastamento do texto e da história, que a aproxima do método originalista de interpretação da Constituição, sendo um frágil critério epistêmico de aferição de ativismo judicial, na medida em que comprometida com pressupostos teóricos estruturados no campo acadêmico e político norte-americano, que é o dos juristas conservadores. No entanto, fugindo das armadilhas que a doutrina originalista americana pode impingir a interpretação constitucional, é possível se entender, sob o prisma hermenêutico, que a "fuga do texto", no sentido de desconsiderar seus limites semânticos, é um indício forte de ativismo judicial, indicativo da ruptura com a estrutura do direito ${ }^{9}$.

Sua terceira categoria é o afastamento dos precedentes, também referida pelos dois autores anteriores, sendo um critério mais apropriado para a tradição jurídica da common law. A quarta categoria não foi encontrada anteriormente: a adoção de fundamentos maximalistas ao invés de minimalistas ao julgar; cuida-se de analisar o grau de ativismo da decisão com base no modelo minimalista ${ }^{10}$ de decisão judicial de Sunstein (1996, p. 6-7), cuja ideia central

\footnotetext{
${ }^{8} \mathrm{O}$ ativismo remedial também não pode ser considerado medida de ativismo a priori, pois pode se tratar, simplesmente, da concretização de direitos fundamentais (o critério está vinculado, certamente, à tradição do liberalismo econômico americano): as Constituições do constitucionalismo contemporâneo estão entrincheiradas com direitos sociais e remédios processuais para impor obrigações prestacionais aos outros poderes.

${ }^{9} \mathrm{O}$ texto é mais que um enunciado linguístico, é um evento que já traz "em si” um compromisso - que é a précompreensão que antecipa esse "em si" - e que é o elemento regulador de qualquer enunciado que façamos a partir daquele texto. O texto da Constituição é um evento (Streck, 2017a, p. 368-371).

${ }^{10}$ Não obstante os interessantes aspectos do modelo de modéstia de Sunstein como estratégia de decisão judicial nas democracias constitucionais, especialmente, em grandes questões políticas e morais que integram as
} 
é "dizer não mais que o necessário para justificar um resultado e deixar, tanto quanto possível, não decidido". Um juiz minimalista tenderá decidir casos estreitamente, deixando, tanto quanto possível, pontos não decididos para que possam ser objeto de consideração em um próximo caso: uma postura incrementalista na qual o juiz procede a um passo de cada vez, fazendo uso construtivo do silêncio. Decisões políticas teorizadas de modo incompleto seriam fonte de estabilidade social (Sunstein apud Teixeira e Oliveira, 2010, p. 294-317).

A quinta categoria de Ernest A. Young é o exercício de amplos poderes remediais, incluindo o que Owen Fiss chamou de "decisões estruturais ou estruturantes”, injunções amplas designadas para reestruturar instituições públicas e conformá-las às normas constitucionais (v.g., a integração racial de escolas públicas - Brown v. Board of Education).

A sexta categoria de Young é decidir casos de acordo com preferências políticas dos juízes, denotando o julgamento orientado pelos resultados (político, ideológico, moral), o qual implica certa dificuldade em demonstrar os estritos vínculos entre o juiz e algum partido, ideologia ou valor/padrão moral como elemento essencial para a tomada da decisão judicial ${ }^{11}$, particularmente, em decisões colegiadas, onde a categoria perde ainda mais força heurística.

Fugindo das classificações dos critérios de ativismo, Green (2009, p. 1199-1200) postula a necessidade de uma perspectiva matizada: a etiqueta "ativista" será útil somente quando um juiz violar standards ou padrões culturais de seu papel judicial, os quais não são formalmente obrigatórios e são somente parcialmente explícitos. As imperfeições em aplicar fontes ortodoxas para debater o ativismo o conduzem a identificar na cultura legal americana standards para a construção do papel judicial: a aplicação interligada de técnicas narrativas e prescrições sobre o "ato de julgar" como cordas de uma rede. Com isso, sugere que o debate sobre o ativismo judicial representa esforços para construir a tradição judicial americana.

Assim, o ativismo judicial é definido por Green (2009, p. 1221-1224) como o abuso de poderes não supervisionados exercidos fora das fronteiras do papel judicial. O debate sobre o ativismo representaria, a rigor, uma discussão cultural sobre o papel judicial, a qual é crucial para operação do próprio sistema legal, e os juristas ocupariam papel especial para

Constituições contemporâneas, não nos parece ser adequado utilizar o binômio minimalista/maximalista como índice qualificativo de ativismo judicial ou self-restraint. Uma decisão judicial poderá ser minimalista e ativista ao mesmo tempo, ou, contrario sensu, maximalista e self-restraint.

${ }^{11}$ Para o modelo atitudinal de adjudicação judicial, os juízes atuariam sem responder a constrangimentos legais ou sociais (opinião pública, partidos), mas decidiriam de acordo com suas próprias filosofias política e moral e uma das formas de tentar identificar preferências políticas dos juízes seria correlacionar sua posição substancial (ideológica) em artigos publicados na imprensa, nos momentos anteriores ao de sua indicação para a Suprema Corte, com o conteúdo posterior de seus votos (Segal e Spaeth, 2002; Cross e Lindquist, 2007, p. 1752-1784). 
desenvolver normas internas (ainda que não obrigatórias) sobre o comportamento judicial. O campo da discricionariedade judicial implicaria mais que a mera liberdade para o juiz decidir como pretende, já que essa discricionariedade carrega uma responsabilidade para decidir. $\mathrm{O}$ conceito de ativismo judicial, desse modo, existe para delinear abusos do poder judicial e da discricionariedade que contraria normas culturais relativas ao papel judicial ${ }^{12}$.

Nessa questão da discricionariedade, Dworkin (2003, p. 451-452) censura o ativismo judicial por considerar que este representaria a primazia do subjetivismo, uma forma virulenta de pragmatismo jurídico: um juiz ativista ignoraria o texto da Constituição, a história de sua promulgação, as decisões anteriores da Suprema Corte que buscaram interpretá-la e as tradições da cultura política, tudo isso para impor a outros poderes do Estado seu próprio entendimento sobre o que a justiça exige. O direito como integridade condena o ativismo e insiste que os juízes devem ajustar suas decisões à prática constitucional e não a ignorar.

Observa-se que a construção do ativismo judicial, e suas concepções, como problema epistemológico na doutrina constitucional americana é recheada de múltiplas abordagens, e, se as doutrinas constitucionais elaboradas no curso da história do direito são formulações que respondem sempre a problemas concretos de seu tempo histórico, é possível circunscrever a gênese do ativismo judicial no âmbito de disputas jurídicas específicas. Efetivamente, não é o registro histórico do termo, no artigo de Schlesinger, que torna o ativismo judicial uma categoria trivial para analisar as instituições judiciais americanas, mas seus contínuos usos a partir dos anos 1950 como instrumento retórico-conceitual com conotação negativa, utilizada por juristas conservadores para atacar a jurisprudência liberal da Corte Warren (Koerner, 2016, p. 239-241). Ocorre que o instrumento mudará de mãos e, com a volta do pêndulo na orientação decisória da Suprema Corte americana, passará a ser utilizada pelos liberais para atacar a jurisprudência conservadora da Corte Rehnquist (Barroso, 2009, p. 324-344) ${ }^{13}$.

Os esforços para apreender os sentidos do ativismo judicial na experiência americana demostram seu caráter contingente (é um problema teórico construído historicamente, cuja gênese está relacionada às batalhas doutrinais da Corte Warren e seu legado, mudando de

\footnotetext{
${ }^{12}$ Algo similar ao que Streck (2017, p. 41-44) propugna em relação ao papel da doutrina jurídica no Brasil: elaborar constrangimentos epistemológicos sobre a jurisprudência, ou seja, construir "censuras significativas" ao trabalho dos juízes, através de uma crítica fundamentada, que permita distinguir boas e más decisões.

${ }^{13}$ Se a doutrina do originalismo foi uma reação conservadora à jurisprudência liberal da Corte Warren, a doutrina do constitucionalismo popular é uma reação liberal à jurisprudência conservadora da Corte Rehnquist e cujo programa radical é a supressão da judicial review, devolvendo ao povo todo o poder decisório de desenvolver os ditames da Constituição (Tushnet, 1999, p. 154-158; Kramer, 2004, p. 242-250).
} 
alvo ao longo do tempo), sua conotação geral negativa (uma categoria de valoração negativa da atuação judicial em contraposição à dimensão positiva deste agir: a autocontenção) e seu traço plurissignificativo (várias concepções são formuladas para estruturar um conceito que possa ser funcional para o controle das decisões judiciais nas democracias constitucionais).

\section{Recepções do ativismo judicial na doutrina constitucional brasileira: uma incursão}

Os percursos do ativismo judicial na experiência americana desvelam a umbilical ligação do conceito com a história do direito, as instituições e a teoria constitucional daquele país, levando a reflexão sobre se é possível sua migração ou transplante para outras realidades. Um conceito exsurgido e desenvolvido no âmbito da tradição jurídica da commom law, com uma Constituição sintética promulgada há mais de duzentos anos, pode ser recepcionado em país da tradição da civil law (Merryman e Péres-Perdomo, 2009, p. 21-27), com uma Constituição analítica e rico catálogo de direitos fundamentais individuais e sociais, e um sistema de controle judicial de constitucionalidade misto, com a complexa junção dos modelos abstrato/concentrado e concreto/difuso de fiscalização de constitucionalidade?

Legrand (2014, p. 11-39) afirma a impossibilidade de transplantes jurídicos diante do fato de que as regras, institutos ou ideias jurídicas são sempre contextuais. Os traços e características particulares da regra jurídica inserem-na na historicidade própria do contexto sócio histórico em que foram engendradas, de tal forma que, na melhor das hipóteses, o que pode ser deslocado de uma jurisdição a outra é, literalmente, uma forma de palavras sem sentido. Isso porque, à medida que atravessa fronteiras, a regra original sofre necessariamente uma mudança que a afeta enquanto regra. Outra regra será recepcionada na jurisdição recipiente. Assim também se passa com o instituto ou ideia (rectius: doutrina) recepcionadas.

Similarmente, Lopez Medina (2009, p. 177-205) foge do modelo de transplantes jurídicos simples, trabalhando a noção de importação de teorias do direito, e como ambientes receptores da América Latina transformam os objetos recebidos dos centros de produção europeu e americano, normalmente, com a desconsideração de pressupostos históricos, sociais e políticos de onde surgiram as teorias recepcionadas. Nesse sentido, a metáfora da migração das ideias constitucionais (Choudry, 2016, p. 21) seria mais frutífera e plástica para se referir a todos os movimentos entre sistemas jurídicos concernentes às doutrinas substantivas e aos 
desenhos institucionais ocorridos na prática do(s) constitucionalismo(s) entre os países ${ }^{14}$. É nessa perspectiva comparada da metáfora de migração de ideias constitucionais que será analisada a recepção e aclimatação do ativismo judicial na doutrina constitucional brasileira.

A obra de Ramos (2010) é importante ponto de partida e um dos referenciais teóricos sobre o assunto no direito brasileiro. Para Ramos (2010, p. 216), o domínio do ativismo refere-se à ultrapassagem das linhas demarcatórias da função jurisdicional, em detrimento, principalmente, da função legislativa, mas, também, da administrativa, inscrevendo-o na tomada de posição sobre os contornos das funções estatais. Mesmo não se atrelando a um específico sistema jurídico, o ativismo estaria mais próximo aos sistemas constitucionais da família romano-germânica, em que o aparato estatal é informado pelo princípio da separação dos poderes: "por ativismo judicial deve-se entender o exercício da função jurisdicional para além dos limites impostos pelo próprio ordenamento que incumbe, institucionalmente, ao Poder Judiciário fazer atuar, resolvendo conflitos de feições subjetivas (conflitos de interesses) e controvérsias jurídicas de natureza objetiva (conflitos normativos)'”.

Há, aqui, clara sinalização valorativa-negativa das práticas ativistas por importarem na desnaturação da atividade típica do poder judiciário. Dentre os parâmetros dogmáticos para aferir o ativismo de decisões judiciais, Ramos (2010, p. 129) desenvolve uma teoria dos graus de controle, correlacionando objetos sujeitos ao controle com a intensidade do rigor da fiscalização: assim, teremos atos não controláveis (v.g., a função de Governo); atos sujeitos a controle mínimo (v.g., o exercício de jurisdição pelo legislativo no controle formal do devido processo legal do impeachment); atos sujeitos a controle médio fraco - o objeto não é imune, mas a fiscalização é de intensidade média fraca - (v.g., atos interna corporis do Parlamento, a função da chefia do Estado e as normas-princípio ${ }^{15}$ como parâmetros de constitucionalidade); atos sujeitos a controle médio forte - a intensidade do controle se acentua - (v.g., o controle de leis em que o parâmetro seja normas-regra e o controle de atos administrativos em que haja discricionariedade); atos sujeitos a controle máximo (v.g., atos administrativos plenamente

\footnotetext{
${ }^{14}$ Migração é uma útil concepção ecumênica no contexto dos movimentos interestatais de ideias constitucionais. Diferentemente de outros termos correntes na literatura comparativista tais como empréstimo, transplante ou fertilização-cruzada, ela não faz presunções sobre as atitudes de doadores e receptores, ou sobre as propriedades dos objetos legais transferidos. Ao invés disso, ela diz respeito a todos os movimentos entre sistemas, visíveis ou ocultas, episódicos ou incrementais, planejadas ou espontâneas, iniciadas pelo doador ou receptor, aceitas ou rejeitadas, adotadas ou adaptadas, concernentes às doutrinas substantivas, aos desenhos institucionais ou a algum mais abstrato ou intangível ethos ou sensibilidade constitucionais (Walker apud Choudry, 2016, p. 316-317).

${ }^{15}$ Haveria um menor grau de vinculatividade dos princípios enquanto parâmetro de constitucionalidade de atos legislativos. Se houver a preservação do núcleo significativo essencial da norma-princípio, ao legislador deve se deferir o poder de realizar acomodações concretizadoras dos princípios (Ramos, 2010, p. 164-165).
} 
vinculados $)^{16}$. E o principal parâmetro de aferição do caráter ativista das decisões consistiria na exigência de que toda interpretação constitucional seja compatível com a amplitude de sentidos projetada pelo texto da norma (vinculação da interpretação ao texto-base).

Sem esboçar um conceito ou concepção sistemática de ativismo judicial, Souza Neto e Sarmento (2015, p. 100-111) formulam um conjunto de parâmetros de autocontenção da atividade jurisdicional, quais sejam: o grau de legitimidade democrática do processo de elaboração do ato normativo questionado (quando mais democrático a elaboração do ato, maior sua presunção de constitucionalidade, como atos normativos aprovados por emendas constitucionais, por plebiscito ou por referendo); a proteção dos pressupostos necessários ao funcionamento da democracia, o primeiro critério procedimentalista de Ely (1980, p. 92 e segs.); a defesa de minorias vulneráveis, o segundo critério procedimentalista de Ely (1980, p. 92 e segs.); a defesa de direitos materialmente fundamentais (condições básicas existenciais da pessoa humana); a época do ato normativo (legislação anterior a 1988 não gozaria de presunção de constitucionalidade); a comparação de capacidades institucionais (é recomendável a autocontenção em matérias que falte expertise técnica ao judiciário).

Os parâmetros desenvolvidos por esses autores para a caracterização do ativismo estão relacionados, mormente, ao objeto de fiscalização constitucional, seja pela supressão de matérias (mecanismo similar ao da "doutrina das questões políticas" americana, transposta ao Brasil por Rui Barbosa) do controle, seja restringindo ou ampliando o rigor da fiscalização sobre matérias específicas, com base em vetores como o elemento temporal (a época da edição do ato), a finalidade/âmbito de proteção do ato (direitos fundamentais) ou a qualidade democrática do ato (grau de participação popular na sua aprovação). E há parâmetros que não se ligam ao objeto de controle, como a teoria da interpretação ("fuga" da textualidade) ou a teoria da especialização das funções estatais (argumento das capacidades institucionais). A não observância desses parâmetros referenciais poderá, contingencialmente, caracterizar uma

\footnotetext{
${ }^{16}$ Seriam fatores de impulsão do ativismo no Brasil: o modelo de Estado social-intervencionista, adotado desde a Constituição de 1934, que pressiona o judiciário na consecução dos fins traçados na Constituição e na fruição imediata de direitos sociais; a expansão do controle abstrato de normas, haja vista os efeitos gerais da decisão judicial sobre a validade da lei, nesta modalidade; o neoconstitucionalismo, como variante teorética que, em matéria de teoria de interpretação, exagera na valorização dos princípios, desprezando regras; a atividade normativa atípica do Supremo Tribunal Federal (função paralegislativa), expressada nos institutos da súmula vinculante e mandado de injunção (este por ter servido como meio para veicular normas gerais no julgamento dos mandados de injunção sobre direito de greve de servidor público (Ramos, 2010, p. 268-304).
} 
decisão judicial como ativista na visão desses autores. Alguns desses parâmetros, no entanto, mais se assimilam a critérios de decisão judicial do que com indicadores de ativismo judicial.

O objetivo, explicitamente, enunciado no trabalho de Azevedo Campos (2014, p. 164) não é elaborar um conjunto dogmático de preceitos para controlar decisões ativistas, e, sim, "descrever" (mas no direito, é possível só descrever, sem prescrever?) o ativismo judicial em múltiplas dimensões. Este seria seu traço essencial: o caráter multidimensional, definindo-o como "o exercício expansivo, não necessariamente ilegítimo, de poderes político-normativos por parte de juízes e cortes em face dos demais atores políticos que (a) deve ser identificado e avaliado segundo os desenhos institucionais estabelecidos pelas Constituições e leis locais; (b) responde aos mais variados fatores institucionais, políticos, sociais e jurídico-culturais presentes em contextos particulares e em momentos históricos distintos; (c) se manifesta por meio de múltiplas dimensões de práticas decisórias”.

Para Azevedo Campos (2014, p. 151-160, 347-348), o núcleo comportamental do ativismo é a autoexpansão do papel político-institucional do judiciário em face de outros atores e instituições de uma ordem constitucional e seu espaço nobre são as questões políticas ou morais complexas, que envolvem normas constitucionais de alta indeterminação semântica e de elevada carga axiológica (hard cases). E a judicialização da política criaria uma estrutura de oportunidades para que as cortes pratiquem ativismo, provocando o judiciário a decidir aquelas questões. As relações institucionais estariam no centro do debate e não a correção (o acerto ou o erro de mérito), constitucional ou moral, das decisões judiciais; tratar-se-ia, dessa maneira, de um conceito relacional. A categoria ativismo judicial nada diria, a priori, sobre a legitimidade ou a ilegitimidade da decisão judicial. O autor identifica, assim, cinco dimensões do ativismo judicial no Supremo Tribunal Federal.

A primeira dimensão delineada (Azevedo Campos, 2010, p. 275-337; 356-358) é a do ativismo metodológico ou interpretativo, que diz respeito ao modo de interpretar e aplicar dispositivos constitucionais, expandindo ou reduzindo significados para além ou aquém dos sentidos mais imediatos e compreensíveis, e até mesmo contra esses sentidos (dimensão de elevada criação judicial). A segunda dimensão é a do ativismo processual (equivalente ao ativismo jurisdicional de Marshall, 2002), o qual se revelaria pelo alargamento que o Supremo Tribunal Federal faz, por conta própria, do campo de aplicação dos processos constitucionais a sua disposição, ampliando hipóteses de cabimento de ações e recursos (na primeira metade do século XX, a doutrina brasileira do habeas corpus fora exemplo dessa postura). 
A dimensão do ativismo estrutural ou horizontal cuida de como o Supremo Tribunal Federal se comporta diante das decisões prévias dos outros poderes (v.g., lei orçamentária ou extradição), e, nesse ponto, ser deferente a capacidade epistêmica ou constitucional dos outros poderes não faria parte da gramática do STF. O ativismo de direitos trataria da expansão dos sentidos normativos das liberdades e da dignidade humana para exigir do Estado a realização de direitos fundamentais, em sentido negativo ou positivo. Enfim, o ativismo antidialógico representaria a postura pela qual o Supremo se autoproclamaria como o titular da palavra final sobre o que diz a Constituição (seria a única dimensão aprioristicamente ilegítima).

Se Ramos (2010) apontara o neoconstitucionalismo (em especial, do ministro Luís Roberto Barroso) como um dos fatores de impulsão do ativismo judicial no Brasil, Torrano (2019, 140-142; 304-314; 407-408) infere que o pós-positivismo seria o “culpado teórico” do ativismo brasileiro, o qual apareceria sob suas formas: o ativismo substantivo, pelo qual atribui-se ao judiciário a competência de substituir juízos políticos e morais do legislador por respostas consideradas, pelo juiz, mais justas, desejáveis ou eficientes. E o ativismo procedimental, colocando-se sob a responsabilidade do judiciário, simplesmente, a tutela da regularidade dos procedimentos legislativos que conduzem ao aperfeiçoamento e a criação do texto legal. Crítico do ativismo substantivo, o autor emula a proposta procedimentalista de Ely (jurisdição constitucional como reforço da democracia) na defesa do ativismo procedimental: a desejável estrita fiscalização das regras procedimentais do devido processo legislativo.

Um de seus críticos mais contundentes, Streck (2017a, 87) qualifica o ativismo judicial como ato de vontade daquele que julga, caracterizado pela corrupção na relação entre os poderes, havendo uma extrapolação dos limites da atuação do judiciário pela via de uma decisão que é tomada a partir de critérios extrajurídicos, assentados na discricionariedade, que abre portas para a arbitrariedade judicial. O espaço da discricionariedade judicial é o da anomia onde o intérprete "põe" o direito arbitrariamente, violando a legislação democrática.

No Brasil, a discricionariedade seria sinônimo de ativismo judicial arbitrário. A crítica hermenêutica do direito, teoria da decisão do autor, postula o controle hermenêutico da decisão pela resposta constitucionalmente adequada, materializada em uma criteriologia decisória: o teste das seis hipóteses pelas quais o juiz poderá deixar de aplicar uma lei: (i) quando a lei for inconstitucional; ou quando for o caso de se aplicar: (ii) critérios de resolução de antinomias, (iii) a interpretação conforme a Constituição, (iv) a nulidade parcial sem redução de texto, ou (v) a nulidade parcial com redução de texto; (vi) quando for o caso de 
não aplicar regra em face de princípio. Fora dessas seis hipóteses, o juiz tem obrigação de aplicar a lei, e, se não o fizer, a decisão será ativista (Streck, 2017b, p. 53-60, 251-268).

Ao teste das seis hipóteses, fundem-se cinco princípios/padrões da decisão jurídica: preservar a autonomia do direito; o controle hermenêutico da interpretação constitucional, para superar a discricionariedade; respeitar a integridade e a coerência do direito; o dever fundamental de justificar as decisões; o direito fundamental a uma resposta correta. Por fim, há situações que o juiz deverá responder a três indagações fundamentais: (i) se está diante de um direito fundamental com exigibilidade; (ii) se o atendimento a esse pedido pode ser, em situações similares, universalizado (concedido às demais pessoas), e, (iii) se, para atender esse direito, está-se fazendo uma transferência de recursos, que fere a igualdade e a isonomia. A resposta negativa a estas indagações, provavelmente, caracterizará a decisão como ativista.

Nessa mesma linha hermenêutica, Tassinari (2013, p. 33-56) circunscreve o ativismo judicial como um problema da teoria do direito (eis que criado no interior do direito), mais precisamente, de teoria da interpretação, equiparando o ativismo como um ato de vontade, ecoando a distinção kelseniana entre o ato de vontade (judicial) que produz normas e o ato de interpretação que produz proposições (a atividade cognitiva da ciência jurídica).

Barroso (2009, p. 71-91) também identifica no ativismo uma questão de vontade, uma escolha de um modo específico e proativo de interpretar a Constituição, expandindo o seu sentido e alcance; porém, aqui, o viés é positivo, materializada de forma exemplar na atribuição da função iluminista às Cortes Supremas, projetando como sendo uma de suas tarefas a de "empurrar a história quando ela emperra", favorecendo a formação de uma democracia não apenas formal (dimensão majoritária), mas substantiva (preservação de valores e direitos fundamentais) e deliberativa (dimensão do debate público com argumentos e persuasão), pois a democracia contemporânea exigiria “votos, direitos e razões". À clássica função contramajoritária da jurisdição constitucional é agregada uma função representativa uma representação argumentativa (Alexy, 2011, p. 155-165) -, cuja legitimidade decorreria da capacidade argumentativa de convencer o auditório (Barroso, 2015, p. 24-50).

Abboud (2016, p. 710) define como ativista toda decisão judicial que se fundamenta em convicções pessoais ou senso de justiça do intérprete em detrimento da legalidade vigente (entendida como legitimidade do sistema jurídico). O ativismo judicial, nessa ótica, deve ser compreendido como a atuação dos juízes a partir de um desapego a legalidade vigente 
(Constituição/leis) para fazer prevalecer, por meio da decisão, sua própria subjetividade. Na dimensão micro, o ativismo judicial consistiria na suspensão da legalidade como critério decisório (decisionismo), e na dimensão macro, como supremacia judicial, um agigantamento em face dos demais poderes, sem respaldo constitucional (Abboud, 2019, n.p.).

Sua tipologia envolve sete espécies de ativismo: o performático, quando o judiciário emprega conceitos sem determinação semântica (expressões performáticas, no sentido de John L. Austin, desprovidas de sentido e, por isso, não passíveis de testes de veracidade ou validade) para suplantar regras legais e constitucionais; o ativismo contra os limites do texto, praticado contra a literalidade do texto; o ativismo messiânico, no qual o julgador ignora regras para implantar o bem comum a ele "revelado"; o ativismo ideológico-moralista, que ocorre quando a autonomia do direito é colonizada pela política; o ativismo populista, que substitui o direito por uma pretensa vontade da população; o ativismo consequencialista, que se dá pela colonização do direito por um discurso economicista ou cientificista, muitas vezes nascendo da importação da teoria da law and economics norte-americana; e o ativismo por inação, caracterizado por uma postura inativa em casos que demandavam a judicial review.

Veríssimo (2013, p. 53-73) sugere que o ativismo judicial é inerente ao controle judicial de constitucionalidade, traduzindo duas séries de problemas: a questão interpretativa derivada da aderência aos materiais normativos dotados de autoridade (quanto maior a distância argumentativa percorrida pela decisão entre o texto constitucional e a norma dele derivada, mais será ela ativista) e a questão da capacidade institucional do judiciário interferir e redesenhar políticas públicas, lidando com decisões programantes (prospectivas e de natureza política, técnica e econômica) e não programadas (regras pré-estabelecidas).

Além de Barroso (2009), a perspectiva de Barboza e Kozicki (2016, p. 733-752) também prescreve um caráter positivo ao ativismo judicial, não o identificando como sinônimo de corte arbitrária, mas como de tribunal não deferente, que enfrenta questões de direitos fundamentais que lhe são colocados, mesmo que estas envolvam decisões sobre matérias políticas. A história do ativismo judicial na Suprema Corte americana mostraria que o ativismo não é algo em si positivo ou negativo, progressista ou conservador, servindo de parâmetro, quer para proteger direitos fundamentais, quer para restringi-los.

É uma proposição similar ao posicionamento de Teixeira (2012, p. 37-58), para quem, mais importante que estabelecer uma definição dogmaticamente precisa de ativismo judicial, é reconhecer tratar-se de um fenômeno que caracteriza uma patologia constitucional 
necessária para a proteção do indivíduo contra as omissões ou os excessos do Estado. Reconhecendo o déficit conceitual na delimitação do termo ativismo judicial, Dimoulis e Lunardi (2013, p. 459-473) sugerem formas e modos de autocontenção como contraponto ao ativismo judicial, objetivando contrabalancear o poder conferido aos juízes.

Nesse sentido, indicam a necessidade de abstenção de juízos de inconstitucionalidade que não possuam plena justificativa e comprometa o equilíbrio entre os poderes. Dentre essas formas de autocontenção, ter-se-ia a crítica a subjetivação-moralização da interpretação constitucional decorrente da teoria da ponderação alexyana, que permitiria declarar a inconstitucionalidade de opções legislativas porque, ou seriam insuficientes para proteger um direito fundamental, ou, ao contrário, ofereceriam proteção excessiva, prejudicando outros direitos fundamentais (o judiciário passa a substituir as ponderações feitas pelo legislador, realizando novas análises políticas e procurando a melhor solução, conforme sua opinião).

Os autores também criticam a ideia de supremacia judicial, quando o judiciário reivindicaria o poder da "última palavra", que no Brasil é temperado pelo fato de o legislador não ser vinculado pelas declarações de inconstitucionalidade, podendo superar as decisões por emenda constitucional (respeitados os limites materiais ao poder de reforma), ou até mesmo de lei idêntica após certo prazo, na expectativa de que a mudança na composição da corte ou no contexto sócio-político mude a orientação jurisprudencial. Apontam ser necessário aplicar o direito constitucional pela equivalência dos poderes estatais na interpretação constitucional, tese conhecida como departmentalism ou nonsupremacy, mostrando todas as interpretações dadas por poderes estatais como igualmente respeitáveis, cada um em seu momento e âmbito de competência, preservando o poder do povo (Dimoulis e Lunardi, 2013, 466-468).

As apropriações teóricas do conceito de ativismo judicial pela doutrina constitucional brasileira permitem algumas inferências: (1) assim como ocorrera na experiência americana, observam-se múltiplas abordagens e concepções no intuito de identificar o fenômeno; (2) há um esforço teórico na construção de parâmetros doutrinários de controle da decisão judicial, que se traduz numa implícita abordagem valorativa negativa ínsita ao fenômeno (se é preciso criar critérios/parâmetros de controle decisório, estes tem a pretensão de prevenir ou corrigir a prática ativista); (3) excluindo a pretensão de neutralidade analítico-descritiva do trabalho de Campos (2014), identifica-se uma razão dualista na recepção do conceito de ativismo judicial na doutrina constitucional brasileira, com uma clivagem em um duplo padrão valorativo: 
(a) de um lado, apreende-se o ativismo como padrão avaliativo de um agir judicial legítimo; aqui, o ativismo é um conceito imediatamente positivo, orientado a concretização de direitos fundamentais, que não viola os arranjos institucionais ou o princípio democrático;

(b) do outro, apreende-se o ativismo como padrão de avaliação de um agir judicial ilegítimo; aqui, o ativismo é um conceito imediatamente negativo e potencialmente promotor de desarranjos na organização funcional dos poderes e carente de legitimação democrática.

Outrossim, percebe-se um descolamento na recepção das concepções de ativismo judicial da doutrina constitucional brasileira em relação às doutrinas americanas: a conotação geral negativa, atributo valorativo da construção histórica do conceito na tradição americana não é verificada no caso brasileiro, onde o ativismo é assimilado pela doutrina constitucional com dupla dimensão valorativa generalizante, a partir da constituição de dois modos de pensar o fenômeno tendo como pressuposto essencial a dimensão valorativa (o valor atribuído ao ativismo). Assim, os critérios epistêmicos de identificação e classificação do ativismo judicial expressariam seus modos de expressão, cuja essencialidade advém de sua dimensão valorativa. O próximo tópico intentará fazer a análise da aclimatação (ajustamento endógeno) do ativismo judicial em parcela da produção acadêmico-jurídica constitucional brasileira.

\section{A aclimatação do ativismo judicial na produção jurídico-acadêmica constitucional}

A doutrina constitucional brasileira aqui selecionada circunscreve-se à parcela da produção jurídica no "espaço jurídico-acadêmico universitário", compreendido como locus privilegiado de produção simbólica dos discursos sobre o direito. Com efeito, a educação jurídica e a pesquisa nos programas de pós-graduação stricto sensu desenvolvem-se em um espaço "institucional” de produção do conhecimento, regulado não apenas pelo controle formal das regras universitárias, mas pela fiscalização material da legitimidade científica. Essa produção regulada do conhecimento jurídico no âmbito da pós-graduação universitária (uma doutrina jurídica acadêmica) e seus impactos na esfera jurídica, marcadamente, a influência nas decisões judiciais e na formatação da política legislativa, se tornam mais significativos se comparados ao imaginário do bacharelismo brasileiro - a doutrina construída pela opinião dos "práticos", ainda que abalizados por um capital simbólico de reconhecimento. A legitimidade do conhecimento jurídico produzido nesse ambiente institucional empresta-lhe forte carga de constrangimento simbólico, tornando-se uma fonte 
de estruturação das próprias narrativas do campo jurídico, reforçando a função estruturante da doutrina jurídica na realização da fenomenologia decisória/aplicativa do Direito.

O recorte de análise abrangeu as teses e dissertações defendidas em Programas de Pós-Graduação em Direito avaliados pela Coordenação de Aperfeiçoamento de Pessoal de Nível Superior (CAPES) com notas 6 no último ciclo avaliativo, na Região Sul e no Estado de São Paulo ${ }^{17}$, amostra composta de 25 teses e dissertações nas quais o ativismo judicial, na área do direito constitucional, surgiu como seu vetor constitutivo e um problema central, não algo periférico, trabalhos em que o ativismo judicial foi teorizado como o próprio objeto de estudo ou seu referencial teórico. Para os fins deste artigo, os trabalhos foram analisados apenas sob o enfoque da dupla dimensão valorativa (razão dualista) referida no tópico retro.

Os Programas de Pós-Graduação stricto sensu em Direito com trabalhos incluídos na amostra foram: a Universidade do Vale do Rio dos Sinos - Unisinos com duas teses e quatro dissertações, nas quais a razão dualista se manifesta: quatro trabalhos ${ }^{18}$ associam o ativismo judicial a práticas judiciais voluntaristas e decisionistas, que representam risco à democracia. $\mathrm{O}$ ativismo é comportamental e derivado de julgamentos realizados por ato de vontade do aplicador não condicionado a critérios jurídicos, com violação à responsabilidade política ao descumprir a Constituição; e dois trabalhos ${ }^{19}$ defendem viés positivo na forma de um ativismo judicial substancialista pela via da interpretação criadora do direito para superar a inércia de realização das promessas constitucionais não concretizadas e das omissões inconstitucionais.

$\mathrm{Na}$ Universidade Federal de Santa Catarina - UFSC foram identificadas duas teses e uma dissertação ${ }^{20}$ e em nenhuma delas o ativismo teve conotação positiva. Particularmente as

\footnotetext{
${ }^{17} \mathrm{O}$ presente artigo apresenta conclusões parciais da tese de doutoramento de seu autor, que está em fase de elaboração, cujo objeto de análise abrange a produção sobre o ativismo judicial dos programas de pós-graduação em direito que tiveram avaliação com notas 6 e 5, no último ciclo avaliativo da CAPES.

${ }_{18}$ "Uma teoria hermenêtica da responsabilidade: os direitos sociais entre o ativismo judicial e a decisão jurídica democrática", 2015, tese de Vinicius de Melo Lima; "O papel do juiz no Estado Democrático de Direito: perspectivas epistemológicas da função judicial no século XXI”, 2016, tese de Letícia Mousquer Ritter; "Ativismo Judicial: uma análise da atuação do judiciário nas experiências brasileira e norte-americana", 2012, dissertação de Clarissa Tassinari; e "O autoritarismo e a incoerência dos fenômenos jurídicos no contexto judicial brasileiro: o garantismo penal e o ativismo judicial", 2018, dissertação de Oswaldo Poll Costa.

19 " O ativismo judicial e a criação do direito pela via da interpretação: as (possíveis) contribuições da filosofia no direito", 2013, dissertação de Paulo Júnior Trindade dos Santos; e "Responsabilidade civil do Estado por omissões inconstitucionais: nos limites entre ativismo judicial e tutela de direitos fundamentais", 2017, dissertação de Dimitrius Boatini.

20 "Déficit político do poder judiciário brasileiro: a falta de efetividade no desempenho de seus poderes institucionais e o ativismo judicial como interferência indevida em área de atuação própria do poder político", 2011, tese de Roberto Basilone Leite; "Superpoder judiciário: o papel do controle de constitucionalidade na consolidação da juristocracia no Brasil", 2018, tese de Eduardo de Carvalho Rêgo; e "Ativismo judicial e princípio da deferência à Administração Pública”, 2020, dissertação de Isaac Kofi Medeiros.
} 
duas teses acentuaram uma carga valorativa "perniciosa" ao ativismo, concebido como a tendência de os juízes interferirem em questões que deveriam ser decididas na arena política. Sob a premissa habermasiana, uma das teses assevera que não caberia ao judiciário proferir decisões sobre questões políticas substantivas ou na definição de políticas públicas.

O ativismo judicial realizado no controle de constitucionalidade caracterizaria uma era marcada por um projeto de superpoder do judiciário (uma juristocracia), na qual os juízes declarariam a inconstitucionalidade de uma norma com base em subjetivismo e desapego à legislação produzida, democraticamente, propagando uma "cultura do inconstitucionalismo".

As oito dissertações selecionadas na Universidade do Vale do Itajaí - UNIVALI reproduziram a dualidade de compreensão do ativismo judicial: quatro ${ }^{21}$ atribuíram conotação geral positiva ao ativismo judicial, três ${ }^{22}$ conferiram-lhe conotação negativa e em uma ${ }^{23}$ delas não foi possível se extrair uma posição avaliativa do fenômeno. Na perspectiva positiva, a percepção valorativa é a de que o ativismo se trataria de algo legítimo, uma postura criativa a ser adotada pelo judiciário na busca da concretização dos direitos fundamentais. Na perspectiva negativa, o ativismo é compreendido como disfuncional, representando incursão insidiosa sobre o núcleo de funções constitucionalmente atribuídas a outros poderes.

Na Universidade Federal do Paraná - UFPR identificou-se uma dissertação ${ }^{24}$ na qual o ativismo é equiparado a decisionismo sem controle social (valor negativo) fundado em três objeções: ausência de legitimidade democrática dos juízes; risco de politização ao fugir dos limites da Constituição; incapacidade institucional para produzir a melhor decisão em certas matérias. As duas dissertações da Pontifícia Universidade Católica do Paraná - PUC/PR possuem distinções no campo valorativo: uma delas ${ }^{25}$ qualifica, positivamente, o fenômeno,

\footnotetext{
21 "O Controle de Políticas Públicas e o Ativismo Judicial frente ao Princípio da Inafastabilidade da Jurisdição", 2011, de Eduardo Hoff Homem; "Ativismo judicial e a efetivação dos direitos constitucionais no Brasil", 2013, de João Batista da Cunha Ocampo Moré; "Os direitos fundamentais e o exercício legítimo do ativismo judicial no Estado Democrático de Direito", 2014, de Mílard Zhaf Alves Lehmkuhl, "Da efetivação dos direitos fundamentais e a sustentabilidade: entre a judicialização da política e o ativismo judicial", 2017, de Orlando da Silva Neto; "Ativismo judicial e a garantia do direito à saúde", 2018, Rafael Nunes Pires Rudolfo.

22 "Ativismo judicial e Estado Democrático de Direito: uma leitura a partir de Antoine Garapon", 2014, de Denise Helena Schild de Oliveira; "Ativismo judicial, políticas públicas e o direito constitucional à saúde", 2014, de Romualdo Paulo Marchinhacki; "A judicialização da saúde e o ativismo judicial: uma análise com base nas ações de fornecimento de medicamentos perante a Vara da Fazenda Pública da Comarca de Itajai", 2020, de Aline Samira Pereira Farhat.

${ }_{23}^{23}$ “Judicialização de políticas públicas, ativismo judicial e implementação dos direitos ambientais: um estudo sob a perspectiva da sustentabilidade", 2020, de Heloisa Husadel Telles.

24 "A sacramentalidade do poder judiciário: a "glória" como legitimação das cortes constitucionais", 2020, de Bruno Rodrigues Zanello.

${ }_{25}$ "A legitimidade democrática da jurisdição constitucional na realização dos direitos fundamentais sociais", 2005, de Estefânia Maria de Queiroz Barboza.
} 
aduzindo que o judiciário deve buscar a realização dos direitos fundamentais sociais por meio de um ativismo judicial de interpretação substantiva dos direitos sociais. A outra ${ }^{26}$ com viés analítico e pretensão de descrever os dois aspectos do fenômeno: sob o ângulo positivo, concretizar direitos fundamentais; sob o negativo, um desvio comportamental dos juízes.

Enfim, na Universidade de São Paulo - USP, foram selecionadas para análise duas teses e quatro dissertações que, novamente, reproduziram o padrão dualista de avaliação do ativismo judicial: em três trabalhos ${ }^{27}$ a categoria possui características negativas sob o influxo do exercício ilegítimo do poder judicial em que o juiz toma decisões com base em convicções pessoais; uma dissertação ${ }^{28}$ evocou seu aspecto positivo, que seria necessário para aplicar valores constitucionais, ainda que excepcionalmente; dois trabalhos ${ }^{29}$ enunciaram a pretensão de neutralidade valorativa com a descrição analítica do fenômeno, seja pela formulação de tipos ideais de ativismo, seja pela perspectiva comparada das doutrinas do ativismo.

\section{Considerações finais}

As metamorfoses da recepção e da aclimatação da categoria epistêmica do ativismo judicial pela doutrina constitucional brasileira mostraram a construção de um padrão dualista inadequado para a correta compreensão e enfrentamento do fenômeno. É possível observar o padrão dualista tanto na sua recepção pelo pensamento jurídico constitucional mainstream, quanto na aclimatação da categoria nas pesquisas produzidas no espaço jurídico-acadêmico universitário, as quais emulam a dupla dimensão valorativa do ativismo judicial. A hipótese de Legrand (2014) e Medina (2009) sobre as metamorfoses do objeto migrado no ambiente de recepção, certo modo, se confirma: o ativismo à brasileira se descola do centro de produção.

Faz-se necessário, por fim, delinear nossa posição crítica contra a razão dualista: o ativismo judicial não pode servir à dupla dimensão valorativa da atuação judicial, pois, do contrário, além de perder força heurística, tornar-se-á ineficaz para aferição do controle das decisões judiciais, podendo ser instrumentalizado para qualquer tipo de avaliação. Com a

\footnotetext{
26“Uma Travessia do Supremo Tribunal Federal sob as Lentes da Judicialização da Política: Da AutoContenção ao Ativismo", 2010, de Roberson Henrique Pozzobon.

27 "O ativismo judicial no Brasil: o caso da verticalização", 2014, tese de Daniel Gustavo Falcão Pimentel dos Reis; "Jurisdição constitucional e ativismo judiciário: análise comparativa entre a atuação do Supremo Tribunal Federal brasileiro e a Suprema Corte estadunidense", 2012, dissertação de Marcelo Mazotti; e "Poder judiciário, ativismo judicial e democracia", 2014, dissertação de Eber de Meira Ferreira.

28 "O ativismo judicial e seus reflexos no processo civil", 2014, dissertação de Pedro Naves Magalhães.

29 "O ativismo judicial na justiça do trabalho", 2011, tese de Luis Fabiano de Assis; "Ativismo judicial: uma análise comparativa no direito constitucional brasileiro e norte-americano”, 2016, Júlio Grostein (dissertação).
} 
tradição hermenêutica (Streck, 2017), entendemos que o ativismo judicial é um conceito interpretativo com conotação geral negativa da atuação judicial, sua identificação depende de critérios jurídicos exclusivos, caracterizando-se como problema hermenêutico relacionado a invasão de elementos metajurídicos no processo interpretativo-decisório Abboud (2015, p. 5). A implementação dos direitos fundamentais deve ser defendida de outros modos a fim de não esvaziar o conceito e, paradoxalmente, fragilizar o próprio intuito concretizador de direitos.

\section{REFERÊNCIAS}

ABBOUD, Georges; LUNELLI, Guilherme. Ativismo judicial e instrumentalidade do processo. Revista dos Tribunais, 2015, p. 21-47.

Processo Constitucional Brasileiro. São Paulo: Revista dos Tribunais, 2019.

ALEXY, Robert. Ponderação, jurisdição constitucional e representação. In: Constitucionalismo Discursivo. Tradução de Luis Afonso Heck. Porto Alegre: Do Advogado, $3^{\mathrm{a}}$ Ed., 2011.

BARBOZA, E. M. Q., KOZICHI, K. (2016). O Judicial Review e o Ativismo Judicial da Suprema Corte Americana na Proteção de Direitos Fundamentais. Espaço Jurídico Journal of Law [EJJL], p. 733-752.

BARROSO, Luís Roberto. Judicialização, ativismo judicial e legitimidade democrática. Rio de Janeiro: Revista de Direito do Estado no. 13, jan./mar., 2009, p. 71-91.

"A razão sem voto: o Supremo Tribunal Federal e o governo da maioria". Brasília: Revista Brasileira de Políticas Públicas, Vol. 5, Número Especial, 2015, p. 24-50.

BAUM, Laurence. A Suprema Corte Americana: uma análise da mais notória e respeitada instituição judiciária do mundo contemporâneo. Rio de Janeiro: Forense, 1987.

BICKEL, Alexander. The Least Dangerous Branch. The Supreme Court at the Bar of Politics. New Haven and London: Yale University Press, 1986.

CAMPOS, Carlos Alexandre de Azevedo. Dimensões do Ativismo Judicial do STF. Rio de Janeiro: Lumen Juris, 2014.

CASTRO, Marcus Faro de. O Supremo Tribunal Federal e a Judicialização da Política. Revista Brasileira de Ciências Sociais, v. 12, n. 34. 1997.

CHOUDHRY, Sujit. Migration as a new metaphor in comparative constitutoinal law. In: CHOURDHRY, Sujit (Ed.). The Migration of Constitutional Ideas. New York: Cambridge University Press: 2006.

CROSS, Frank B., LINDQUIST, Stefanie A. The Scientific Study of Judicial Activism. Minnesota Law Review, Vol. 91: 1752, 2007, p. 1752-1784.

DIMOULIS, Dimitri, LUNARDI, Soraya. Teorias explicativas da Constituição brasileira. In: DIMOULIS, Dimitri et al. Ativismo e Autocontenção Judicial no Controle de Constitucionalidade. In: As Novas Faces do Ativismo Judicial. Marcelo Novelino, André Fellet e Daniel Giotti de Paula (Org.). Salvador: Juspodivm, 2013.

DWORKIN, Ronald. O Império do Direito. Jefferson Luis Camargo (Trad.). São Paulo: Martins Fontes: 2003.

ELY, Jonh Hart. Democracy and Distrust: A Theory of Judicial Review. Cambridge: Harvard University Press, 1980.

FRIEDMAN, Barry. The Birth of an Academic Obsession: The History of the Countermajoritarian Difficulty, Part Five. Yale Law Journal, Volume 112, 2002, p. 153-259.

GREEN, Craig. An Intellectual History of Judicial Activism. Emory Law Journal, Legal Studies Research Paper Series, Vol. 58, 2009, p. 1199-1200.

HIRSCHL, Ran. Towards Juristocracy: The Origins and Consequences of the New Constitutionalism. Harvard University Press, 2007. 
KMIEC, Keenan D. The Origin and Current Meanings of “Judicial Activism". Califórnia Law Review, Vol. 92: 1441, 2004, p. 1441-1477.

KOERNER, Andrei. O Ativismo Judicial como Problema Intelectual e Político nos Estados Unidos: uma análise crítica. Revista Lua Nova, São Paulo, 2016, p. 239-241.

KRAMER, Larry. The People Themselves: Popular Constitutionalism and Judicial Review. New Jersey: Oxford University Press, 2004.

LEGRAND, Pierre. A Impossibilidade de Transplantes Jurídicos. Tradução de Gustavo Castagna Machado. Cadernos do Programa de Pós-Graduação em Direito da UFRGS, Vol. 9, n. 01, 2014, p. 11-39.

MARSHALL, William. Conservatives and the Seven Sins of Judicial Activism. University of Colorado Law Review, Vol. 73, 2002, p. 101-139.

MEDINA. Diego E. López. La Cartografía de la Teoría Jurídica: Dialógo com los Críticos. In: Teoría del Derecho y Transplantes Jurídicos. Daniel Bonilla Maldonado (Editor). Bogotá: Siglo del Hombre Editores, 2009.

MERRYMAN, John Henry, PÉRES-PERDOMO, Rogelio. A Tradição da Civil Law. Uma Introdução aos Sistemas Jurídicos da Europa e da América Latina. Tradução de Cássio Casagrande. Porto Alegre: Sérgio Antonio Fabris, 2009.

MOTTA, Luiz Eduardo; MOTA, Maurício. O Estado Democrático de Direito em Questão. Teorias críticas da judicialização da política. Rio de Janeiro: Elsevier, 2011.

POSCHER, Ralf. A mão de Midas: quando conceitos se tornam jurídicos ou esvaziam o debate HartDworkin. Tradução de Rafael Giorgio Dalla Barba. In: Revista de Estudos Constitucionais, Hermenêutica e Teoria do Direito (RECHTD) 10(1): 2-13, janeiro-abril 2018.

RAMOS, Elival da Silva. Ativismo Judicial. Parâmetros Dogmáticos. São Paulo: Saraiva, 2010.

SOUZA NETO, Cláudio Pereira, SARMENTO, Daniel. Controle de Constitucionalidade e Democracia: Algumas Teorias e Parâmetros de Ativismo. In: SARMENTO, Daniel (Org.). Jurisdição Constitucional e Política. Rio de Janeiro: Grupo Gen, 2015.

STRECK, Lenio Luiz. Verdade e Consenso. Constituição, Hermenêutica e Teorias Discursivas. 6. Ed. São Paulo: Saraiva, 2017a.

Dicionário de Hermenêutica: quarenta temas fundamentais da Teoria do Direito à luz da Crítica Hermenêutica do Direito. Belo Horizonte: Letramento, 2017b.

SUSTEIN, Cass. Foreward: Leaving Things Undecided. Harvard Law Review, Vol. 110:4, 1996.

. Decisões políticas teorizadas de modo incompleto no direito constitucional. Tradução de Letícia Borges Thomas. In: TEIXEIRA, Anderson Vichinkeski Teixeira; SOMENSI, Elton. Correntes Contemporâneas do Pensamento Jurídico. São Paulo: Manole, 2010.

SWEET, Alec Stone. Governing with judges. Constitutional Politics in Europe. New York: Oxford University Press, 2004.

TATE, Neal C.; VALLINDER, Torbjörn. The Global Expansion of Judicial Power. New York: New York University Press, 1995.

TASSINARI, Clarissa. Jurisdição e Ativismo Judicial: limite da atuação do Judiciário. Porto Alegre: Do Advogado, 2013.

TEIXEIRA, Anderson Vichinkeski. Ativismo judicial: nos limites entre racionalidade jurídica e decisão política. Revista Direito GV, Volume 15. São Paulo, JAN-JUN 2012, p. 37-58.

TORRANO, Bruno. Democracia e Respeito à Lei. Entre Positivismo Jurídico, Pós-Positivismo e Pragmatismo. 2. Ed. Belo Horizonte: Fórum, 2019.

TUSHNET, Mark. Taking the Constitution Away from the Courts. Princeton: Princeton University Press. 1999.

VALLE, Vanice Regina Lírio (Org.). Ativismo Jurisdicional e o Supremo Tribunal Federal. Laboratório de Análise Jurisprudencial do STF. Curitiba: Juruá, 2012. 
VERÍSSIMO, Marcos Paulo. Controle de Constitucionalidade e Ativismo Judicial. In: WANG, Daniel Wei Liang (Org.). Constituição e política na democracia. Aproximações entre direito e ciência política. São Paulo: Marcial Pons, 2013.

VERONESE, Alexandre. A judicialização da política na América latina: panorama do debate teórico contemporâneo. Escritos, Revista da Fundação Casa de Rui Barbosa, Ano 3, n. 3, 2019.

YOUNG, Ernest A. Judicial Activism and Conservative Politics. Colorado Law Review, Volume 73, número 4, 2002, p. 1.139-1.216.

WERNECK VIANNA, Luiz et al. A judicialização da política e das relações sociais no Brasil. Rio de Janeiro: Revan, 1999. 